\title{
$O$ desflorestamento e a legislação ambiental em projetos de assentamento no estado do Amapá
}

No estado do Amapá, a agricultura familiar nos projetos de assentamentos é responsável por grande parte do desflorestamento. Esta atividade é desenvolvida através de roças, que possui um sistema de revezamento de terras, caracterizando o chamado 'desmatamento silencioso', que são difíceis de serem detectados, variando em uma área de no máximo 3 hectares. Sem a distinção do desmatamento legal do ilegal, não é possível direcionar ações e políticas públicas aplicadas diretamente às atividades ilegais. $O$ objetivo principal desta pesquisa foi analisar o desflorestamento e a legislação ambiental em Projeto de Assentamento (PA). O principal fato para a causa do avanço do desmatamento é que a maioria dos projetos de assentamento não têm planejamento e as áreas demarcadas para realizar o PA não são escolhidas em função das suas características agrícolas, além do pouco conhecimento das famílias assentadas sobre a legislação ambiental, os quais dificilmente têm percepção de resguardar as Áreas de Preservação Permanente (APP) ou as Reservas Legais (RL), causando assim o desmatamento ilegal.

Palavras-chave: Projeto de assentamento; Autorizações de desmatamento; Legislação ambiental.

\section{Deforestation and environmental legislation in settlement projects in the state of Amapá}

In the state of Amapá, family farming in settlement projects is responsible for much of the deforestation. This activity is carried out through fields, which have relay system featuring so-called 'silent deforestation', which are difficult to detect, varying in an area of up to 3 hectares. Without distinguishing between legal and illegal deforestation, it is not possible to direct public actions and policies applied directly to illegal activities. The main objective of this research was to analyze deforestation and environmental legislation in Settlement Project (PA). The main fact for the cause of advancing deforestation is that most settlement projects are unplanned and the areas demarcated to carry out the PA are not chosen because of their agricultural characteristics, and the lack of knowledge of settled families about environmental legislation., which are hardly aware of safeguarding Permanent Preservation Areas (APP) or Legal Reserves (RL), thus causing illegal deforestation.

Keywords: Settlement project; Deforestation permits; Environmental legislation.

Topic: Planejamento, Gestão e Políticas Públicas Ambientais

Reviewed anonymously in the process of blind peer.
Received: 28/06/2019

Approved: 28/07/2019
José Douglas Monteiro da Costa (iD)

Universidade Federal do Amapá, Brasil

http://lattes.cnpq.br/7756200053701768

http://orcid.org/0000-0002-1710-7686

cientistaambiental2012@gmail.com
Referencing this:

COSTA, J. D. M.. O desflorestamento e a legislação ambiental em projetos de assentamento no estado do Amapá. Revista lberoAmericana de Ciências Ambientais, v.10, n.4, p.337-344, 2019. DOI: http://doi.org/10.6008/CBPC2179-6858.2019.004.0026 


\section{INTRODUÇÃO}

O desflorestamento legal, diferente das atividades ilegais contra a biodiversidade, tem o objetivo em conciliar os aspectos ambientais com o econômico em uma sociedade. Todavia, deve ser uma atividade planejada, monitorada e fiscalizada pelo Estado, para não comprometer o meio ambiente e o interesse público. Conforme Grisi (2000) e Milaré (2009) o desflorestamento é um processo, de origem antrópica, e tem o objetivo de supressão da cobertura vegetal nativa de uma mata ou floresta, para a finalidade de expansão urbana, agricultura e utilização de madeira, dentre outros.

A floresta urbanizada, de acordo com Becker $(1995,2001)$, e a condição de vida nos assentamentos e cidades contribuem para os maiores problemas ambientais. A vegetação nativa na Amazônia vem sofrendo modificações durante as últimas décadas (BECKER, 2005). A agricultura (FEARNSIDE, 1999), pecuária (MARGULIS, 2003; WALKER et al., 2000), e a exploração de madeira (FEARNSIDE, 2003) são as maiores responsáveis pelo desflorestamento. Os assentamentos são os principais causadores de desflorestamento na Amazônia nos últimos anos. O desflorestamento tem sido destacado principalmente pela mudança no tamanho dos polígonos, passando de grande para pequenas áreas (ALENCAR et al., 2013).

A agricultura é uma das atividades de maior causa do desflorestamento (KITAMURA, 1994), que chega aproximadamente a 50\% do total de desmatamento (HOMMA et al., 1995). Fearnside (2001) destaca que a agricultura em assentamentos rurais faz parte das atividades que mais causam impactos a vegetação nativa. Para Batista (2009), os desflorestamentos realizados nos projetos de colonização e assentamentos, somam $25,5 \%$ do total de áreas desmatadas no estado do Amapá.

O desflorestamento realizado sem autorização emitida pelos órgãos ambientais competentes é denominado de ilegal ou não autorizado, e traz consequências negativas ao meio ambiente. No estado do Amapá, a agricultura familiar é responsável por grande parte do desflorestamento, esta atividade é desenvolvida através de roças, que possui um sistema de revezamento de terras, variando em uma área de no máximo 3 hectares (DOMINGUES et al., 2004; AMAPÁ, 2009). Este revezamento correlacionado com a variação da área produz constante desmate e queimada, caracterizando o chamado desmatamento silencioso, que são difíceis de serem detectados por imagens de satélites (DOMINGUES et al., 2004).

Um dos maiores desafios atuais consiste em diferenciar o desflorestamento ilegal do legal, para que se possa efetivamente extinguir o ilegal e promover políticas públicas para reduzir a supressão legal, sem prejuízo do desenvolvimento local. O desflorestamento legal, diferente das atividades ilegais contra a biodiversidade, tem o objetivo em conciliar os aspectos ambientais com o econômico de uma sociedade. Todavia, deve ser uma atividade planejada, monitorada e fiscalizada pelo Estado, para não comprometer o meio ambiente e o interesse público.

Com a Lei Federal no 11.284, de 2 de março de 2006, a gestão florestal passou a ser atribuição do Estado, executada pela Secretaria de Meio Ambiente do Estado do Amapá (SEMA) e pelo Instituto de Meio Ambiente e Ordenamento Territorial do Estado do Amapá (IMAP). As autorizações são emitidas pelo IMAP usando o Sistema de Produtos Florestais (SISPROF) do Instituto Brasileiro do Meio Ambiente e dos Recursos 
Naturais Renováveis (IBAMA), em conformidade com a Instrução Normativa № 3, de 4 de março de 2002 IBAMA e a Instrução Normativa no 75, de 25 de agosto de 2005-IBAMA, que tratam de autorizações de desmatamento.

\section{METODOLOGIA}

Este trabalho buscou analisar o desflorestamento e a legislação ambiental em Projeto de Assentamento - PA no Estado do Amapá. Para isso, fizemos estudos sobre o desflorestamento e levantamento da legislação na esfera Federal. O objetivo principal deste trabalho foi analisar o desflorestamento e a legislação ambiental em Projeto de Assentamento - PA no estado do Amapá

\section{DISCUSSÃO TEÓRICA}

\section{O Desflorestamento Legal no Estado do Amapá: Políticas e legislações aplicadas ao desflorestamento legal no estado do Amapá}

O primeiro Código Florestal estabeleceu limites para exploração da vegetação nativa. No artigo 83, caracterizava como crimes florestais a remoção ou supressão de florestas sem a anuência da autoridade florestal competente (AHRENS, 2003). O Código Florestal de 1965 foi mais estrito no controle do desflorestamento, pois a permissão para a supressão da vegetação estava condicionada à autorização do Poder Executivo Federal (GONZÁLES et al., 2006).

No Estado do Amapá, em 1991, com a promulgação da Constituição do Estado, que dedicou um capitulo direcionado ao meio ambiente, estabeleceu que apenas com autorização ambiental a execução de obras, atividades industriais, processos produtivos, empreendimentos e a exploração de recursos naturais de qualquer espécie, quer pelo setor público, quer pelo setor privado, será admitida se houver resguardo do meio ambiente ecologicamente equilibrado, ficando proibida a exploração desordenada e predatória das espécies nativas do Estado (AMAPÁ, 1991).

O Decreto no 1.282 (BRASIL, 1994) trazia em seu artigo 8o, no § 3 que a autorização de desmatamento seria emitida pela autoridade competente, após vistoria prévia. A Portaria no 48 (BRASIL, 1995) nos artigos 21 a 31얼 definia que a autorização de desmate seria permitida, desde que o proprietário mantivesse uma área de reserva legal de, no mínimo, 50\% da cobertura nativa. Em 1999, o Código de proteção ambiental do Estado do Amapá, foi publicado objetivando colaborar com os cidadãos amapaenses suas responsabilidades ambientais, pois existia a preocupação crescente com a questão ambiental e necessidade da participação ativa da sociedade nas políticas ambientais (AMAPÁ, 1999).

Em 2002 foram definidos procedimentos de conversão de uso do solo através de autorização de desmatamento nos imóveis e propriedades rurais de até três hectares, em Projetos de Assentamento da Reforma Agrária na Amazônia Legal (BRASIL, 2002). A emissão de autorização deve ser concedida após vistoria feita pelo órgão competente, obedecendo aos limites máximos permitidos de desmatamento e de manutenção da Reserva Legal e das Áreas de Preservação Permanente (BRASIL, 2005). 
A SEMA-AP, com a preocupação do avanço do desflorestamento sobre a vegetação nativa, desenvolveu através da sua Divisão de Geoprocessamento - DGEO, desde 2003 o monitoramento sistemático da dinâmica de uso da cobertura vegetal do estado com o auxílio de imagens de satélite (AMAPÁ, 2005). Os Relatórios técnicos de desmatamento orientam a Secretaria nas ações de controle e educação ambiental uma vez que permite identificar as áreas que sofrem maiores pressões antrópicas sobre o uso e exploração dos recursos naturais no Estado (AMAPÁ, 2005).

A gestão florestal do Estado do Amapá, até o início do ano de 2007 era de responsabilidade do Governo Federal, por intermédio do IBAMA. Com a criação da Lei Federal no 11.284, de 2 de março de 2006 passou a ser do Estado do Amapá, que inicialmente foi executada pela SEMA. A partir do segundo semestre de 2007, as autorizações de desmatamento começaram a ser emitidas pelo IMAP, com o auxílio do Sistema de Produtos Florestais - SISPROF do IBAMA. Permanecendo para o IBAMA somente a responsabilidade sobre o procedimento administrativo referente à supressão de vegetação nativa, localizado no domínio da União.

Atualmente as autorizações de desmate são emitidas de acordo com a Lei no 12.651, de 25 de maio de 2012, com a Instrução Normativa no 3, de 4 de março de 2002 - IBAMA e a Instrução Normativa no 75, de 25 de agosto de 2005-IBAMA. Estas legislações definem os procedimentos e documentação necessária par a obtenção de autorização de desmatamento.

Com o Novo Código Florestal, a Lei no 12.651, de 25 de maio de 2012, a delimitação da área de Reserva Legal está nos arts. 12 a 16 do capítulo IV que discorrem que todo imóvel rural deve manter área com cobertura de vegetação nativa, a título de Reserva Legal, observados na Amazônia Legal os 80\% (oitenta por cento), no imóvel situado em área de florestas, 35\% (trinta e cinco por cento), no imóvel situado em área de cerrado e $20 \%$ (vinte por cento), no imóvel situado em área de campos gerais, excetuados os casos previstos no art. 68 desta Lei.

\section{Procedimentos para a obtenção da autorização de desmatamento no Estado do Amapá}

Para a obtenção das autorizações de desmatamento, os interessados instruir processo junto ao IMAP, com as documentações necessárias exigidas de acordo com Instrução Normativa no 3 , de 4 de março de 2002. Os procedimentos que devem ser adotados para obtenção de uma autorização de desmatamento são realizados em duas etapas. A primeira deve ser realizada pelo requerente onde o interessado em efetuar a supressão da vegetação de uma área deve protocolar, na sede do IMAP, o requerimento e os documentos necessários (BRASIL, 2002, 2003).

A segunda etapa compete ao órgão, o qual foi solicitado a autorização, onde o requerimento e os documentos são despachados para que seja feita a análise inicial da documentação. Com a documentação analisada e devidamente de acordo com a legislação, o requerimento é deferido e protocolado, criando, então, um processo administrativo com capa e etiqueta padrão, numeração do processo, assunto e data de entrada do requerimento.

O processo administrativo será encaminhado para o setor jurídico e em seguida para a análise técnica. Após o deferimento do processo, é necessária a execução de vistoria técnica na área. O parecer do 
vistoriador, sendo favorável, o solicitante estará autorizado a executar a supressão, mediante a emissão da autorização e cumprimento das condicionantes.

\section{Documentação necessária para o requerimento da autorização de desmatamento no estado do Amapá}

A documentação necessária para o requerimento das autorizações de supressão em propriedades rurais com área de até três hectares, com a finalidade de agricultura familiar, o interessado deverá apresentar o requerimento simplificado, juntamente com o Documento Informativo da Propriedade (DIPRO) e também deve-se apresentar o documento de identificação do proprietário, prova de propriedade ou posse, cópia do contrato de arrendamento ou comodato, quando for o caso, procuração com poderes específicos para o pleito, quando for o caso, declaração de manutenção da área de preservação permanente, documento que comprove a averbação da Área de Reserva Legal e Termo de Compromisso de Averbação de Reserva Legal (TCARL).

Para concessão de autorização em propriedades com área superior a três hectares, aplicam-se as mesmas documentações exigidas em áreas de até três hectares, acrescidos de inventário florestal, croqui da propriedade, indicando área de reserva legal, áreas de preservação permanente, áreas com benfeitorias, áreas encapoeiradas, área solicitada para conversão, área disponível para uso futuro, área com agricultura familiar, área com pastagem, tipologias vegetais, hidrografia, sistema viário e confrontantes. e se possível, cópia da imagem de satélite com delimitação da propriedade e da área proposta para supressão, com escala de $1: 10.000$ a $1: 40.000$.

Para o caso específico dos Assentamentos Rurais, deve-se apresentar as mesmas documentações exigidas em áreas de até e superiores a três hectares, com o documento de criação do projeto de assentamento, com a planta geral do assentamento, contendo: as áreas de conservação e de utilização; demais áreas; hidrografia; confrontantes; coordenadas geográficas; escala e convenções. As plantas devem conter a identificação das áreas de conservação e informar se elas estão averbadas ou não à Relação de Beneficiários do Sistema de Informação de Projetos de Reforma Agrária (SISPRA) e suas respectivas parcelas no Projeto de Assentamento, no caso de projetos do Instituto Nacional de Colonização e Reforma Agrária (INCRA).

\section{Desflorestamento Legal e llegal no estado do Amapá}

O Estado do Amapá no ano de 2008 teve a maior taxa de desmatamento da última década, com aproximadamente $100 \mathrm{~km}^{2}$ (INPE, 2015), o que resultou no Plano de Prevenção e Controle do Desmatamento e Queimadas no Estado do Amapá - PPCDAP. O PPCDAP teve como principal objetivo a redução de desmatamentos ilegais em áreas consideradas críticas e a garantia da manutenção de suas florestas nativas, com o auxílio de ações de monitoramento, licenciamento e fiscalização (AMAPÁ, 2009). Em 1997, o IBAMA autorizou o desmate de $8,1 \mathrm{~km}^{2}$, e foi detectada, através de imagens de satélites pelo INPE, uma área de $18 \mathrm{~km}^{2}$ de desflorestamento, ou seja, a área autorizada correspondeu aproximadamente a $45 \%$ do desmatamento total no estado do Amapá (BRASIL, 2003). 
No ano de 1998 , foi autorizado o desmatamento de $8,4 \mathrm{~km}^{2}$, que representou $28 \%$ do total de desflorestamento informado pelo INPE. Em relação ao ano de 1999, o IBAMA emitiu autorizações de desmatamento totalizando aproximadamente $20 \mathrm{~km}^{2}$, sendo que o INPE não conseguiu realizar o levantamento de desmatamento, devido a ocorrência de muitas nuvens (BRASIL, 2003).

Alguns estudos no estado do Amapá já quantificaram o desmatamento legal. Em 2009 e 2010, no município de Tartarugalzinho foi desmatado 97,78\%, sem autorização, do total 1618,00ha, detectado pela SEMA (COSTA et al., 2017). Os assentamentos são os principais causadores de desflorestamento na Amazônia nos últimos anos (FEARNSIDE, 1999, 2001). O desflorestamento tem sido destacado principalmente pela mudança no tamanho dos polígonos, passando de grande para pequenas áreas (ALENCAR et al., 2016; BRASIL, 2013). Para Alencar et al. (2016), as áreas de polígonos de floresta desmatadas no período de 2010 a 2014 no estado do Amapá, foram de pequenas áreas, realizadas em até 10ha.

A agricultura familiar nos projetos de assentamentos, contribui com grande parte na taxa de desmatamento, através de revezamento de terras (DOMINGUES et al., 2004; AMAPÁ, 2009). Este revezamento, correlacionado com a variação da área produz constante desmate e queimada, caracterizando o chamado desmatamento silencioso, é que são difíceis de serem detectados por imagens de satélites (DOMINGUES et al., 2004).

De acordo pesquisa realizada por Batista (2009), para o período compreendido entre os anos 2001 a 2006, os desmatamentos ocorridos nos projetos de assentamentos, principalmente, os de jurisdição do Instituto Nacional de Colonização e Reforma Agrária (INCRA-AP), representou um percentual de $25,5 \%$ (38.358ha) do total de áreas desmatadas no estado do Amapá. Assim como em outros estudos, a estimativa de desmatamento nos assentamentos vem crescendo. No biênio 2013-2014, o desmatamento foi de $21,27 \mathrm{~km}^{2}$, sendo que, a maior incidência de desmatamentos ocorreu nos assentamentos localizados na região central e ao norte do estado (AMAPÁ, 2016).

O PA Cedro possuía 95,17\% de área de floresta em sua criação, em 1996. Não podemos descartar a importância das legislações vigentes, com o objetivo de reservar áreas florestadas. Em 2002 foram definidos procedimentos de conversão de uso do solo através de autorização de desmatamento nos imóveis e propriedades rurais de até três hectares, em Projetos de Assentamento da Reforma Agrária na Amazônia Legal (BRASIL, 2002). A emissão de autorização deve ser concedida após vistoria feita pelo órgão competente, obedecendo aos limites máximos permitidos de desmatamento e de manutenção da Reserva Legal e das Áreas de Preservação Permanente (BRASIL, 2005).

No período de 2002 a 2009 foi autorizada para desflorestamento a supressão de aproximadamente $404 \mathrm{~km}^{2}$ no Estado do Amapá, conforme o relatório do Sistema de Produtos Florestais - SISPROF (IBAMA, 2009). De acordo com INPE $(2015)$ e AMAPÁ $(2005,2009,2010)$ foi detectada uma taxa de desmatamento de aproximadamente $784 \mathrm{~km}^{2}$ no Estado do Amapá, no período de 2002 a 2009. Para este período a área autorizada chegou em aproximadamente $51,5 \%$ do total de desmate detectado. 


\section{CONCLUSÕES}

O principal fato para a causa do avanço do desmatamento é que a maioria dos projetos de assentamento não têm planejamento e as áreas demarcadas para realizar o PA não são escolhidas em função das suas características agrícolas, além do pouco conhecimento das famílias assentadas sobre a legislação ambiental, os quais dificilmente têm percepção de resguardar as Áreas de Preservação Permanente (APP) ou as Reservas Legais (RL), causando assim o desmatamento ilegal.

O Novo Código Florestal destacou a intenção de promover ações para combater desmatamentos e queimadas, adoção de práticas mais sustentáveis e mudanças na política ambiental. Contudo, percebeu-se aumento nas taxas de desmatamento nos projetos de assentamentos, associado à alteração na referência da cota dos rios para o estabelecimento das Áreas de Proteção Permanente (APPs) e da regra de recomposição florestal que reduz as exigências para as pequenas propriedades.

Os órgãos responsáveis pelas atividades de fiscalização e cumprimento das legislações ambientais possuem dificuldades de acesso a muitos assentamentos e também a extensa área que os compõem, e consequentemente é cada vez mais difícil promover ações de controle e fiscalização dos projetos de assentamento de forma eficiente.

\section{REFERÊNCIAS}

ALENCAR, A.; PEREIRA, C.; CASTRO, I.; CARDOSO, A.; SOUZA, L.; COSTA, R.; BENTES, A. J.; STELLA, O.; AZEVEDO, A.; GOMES, J.; NOVAES, R.. Desmatamento nos Assentamentos da Amazônia: Histórico, Tendências e Oportunidades. Brasília: IPAM, 2016.

AMAPÁ. Plano Anual de Outorga Florestal 2015. Macapá: IEF, 2014.

AMAPÁ. Programa de Prevenção e Controle do Desmatamento e Queimadas do Estado do Amapá: PPCDAP. Macapá: SEMA, 2009.

AMAPÁ. Relatório Técnico de Desmatamento no Estado do Amapá, referente a 2004. Macapá: SEMA, 2005.

AMAPÁ. Relatório Técnico de Desmatamento no Estado do Amapá, referente ao período 2011 a 2012. Macapá: SEMA, 2014.

AMAPÁ. Relatório Técnico de Desmatamento no Estado do Amapá, referente ao período 2013 a 2014. Macapá: SEMA, 2016.

ANDERSON, A.. Diretrizes de um Programa de REDD+ para o Estado do Amapá. Macapá: IEFAm, 2015.

ASNER, G. P.. Cloud cover in Landsat observations of the Brazilian Amazon. International Journal of Remote Sensing, Bristol, v.22, n.18, p.3855-3862, 2001. DOI: http://doi.org/10.1080/01431160010006926

BATISTA, E. M.. O desmatamento em Projetos de Colonização e Reforma Agrária situados no Estado do Amapá. In: SIMPÓSIO BRASILEIRO DE SENSORIAMENTO REMOTO, 14. Anais. Natal: 2009.
BECKER, B. K.. Amazônia: Geopolítica na Virada do III Milênio. Rio de Janeiro: Garamond, 2005.

BECKER, B. K.. Mesa Redonda: Sensoriamento Remoto e a questão urbana na Amazônia. In: SIMPÓSIO BRASILEIRO DE SENSORIAMENTO REMOTO, 10. Anais. Foz do Iguaçu: 2001.

BECKER, B. K.. Undoing Myths: The Amazon: An Urbanized forest. In: CLÜSENER, G. M.; SACHS, I.. Brazilian Perspectives on sustainable development of the Amazon region: Man and Biosphere Series. Paris: UNESCO, 1995. p.53-89.

BRASIL. Ministério do Meio Ambiente. Informativo técnico: Desmatamento. Brasília: MMA, 2003.

BRASIL. Ministério do Meio Ambiente. Plano de Ação para prevenção e controle do desmatamento na Amazônia Legal: PPCDAM 3a fase. Brasília: MMA, 2013.

CÂMARA, G.; VALERIANO, D. M.; SOARES, J. V.. Metodologia para o Cálculo da Taxa Anual de Desmatamento na Amazônia Legal. São José dos Campos: INPE, 2006.

COSTA, J. D. M.; CARMONA, S. L. S.; FUNI, C.. Análise espacial do desflorestamento legal no estado do Amapá. In: SIMPÓSIO BRASILEIRO DE SENSORIAMENTO REMOTO, 18. Anais. Santos: Mendes Convention Center, 2017.

DOMINGUES, E.; PEREIRA, R. F.; GAMA, A. M. R. C.; RIBEIRO, G. V.; ALVES, P. S. P. F.; FERNANDES, N. P.; LEITE, P. F.; GOMES, S. O.; AQUINO, A. M. F. A.; LIMA, S. S. C.. Cobertura e Uso da Terra no Estado do Amapá. Rio de Janeiro: IBGE, 2004. 
DRUMMOND, J. A.; DIAS, T. C. A. C.; BRITO, D. M. C.. Atlas das Unidades de Conservação do Estado do Amapá. Macapá: SEMA, 2008.

FEARNSIDE, P. M.. A floresta amazônica nas mudanças globais. Manaus: INPA, 2003.

FEARNSIDE, P. M.. Combate ao desmatamento na Amazônia brasileira. Cadernos da Biodiversidade, Curitiba, v.2, n.2, p.12-29, 1999.

FEARNSIDE, P. M.. Land-Tenure Issues as Factors in Environmental Destruction in Brazilian Amazonia: the case of southern Pará. World Development, v.29, n.8, p.1361-1372, 2001. DOI: https://doi.org/10.1016/S0305-750X(01)00039-0

FLORENZANO, T. G.. Geomorfologia: conceitos e tecnologias atuais. São Paulo: Oficina de Textos, 2008.

GOLFARI, L.; CASER, R. L.; MOURA, V. P. G.. Zoneamento ecológico esquemático para reflorestamento no Brasil. Belo Horizonte: PRODEPEF, 1978.

GRISI, B. M.. Glossário de ecologia e ciências ambientais. 2 ed. João Pessoa: UFPB, 2000.

HOMMA, A. K. O.; WALKER, R. T.; SEATENA, E. N.; CONTO, A. J.; CARVALHO, R. A.; SANTOS, A. L. M.. Redução dos Desmatamentos na Amazônia: política agrícola ou ambiental?. In: CONGRESSO BRASILEIRO DE ECONOMIA E SOCIOLOGIA RURAL, 33. Anais. Curitiba: 1995.

IBGE. Instituto Brasileiro de Geografia e Estatística. Censo Demográfico 2010. Rio de Janeiro: IBGE, 2012.

ICMBIO. Instituto Chico Mendes de Conservação da Biodiversidade. Plano de manejo da Floresta Nacional do Amapá: Volume I: Diagnóstico.. Macapá: ICMBio, 2014.
ICV. Instituto Centro de Vida. Análise do desmatamento em Mato Grosso (PRODES/2016). Cuiabá: ICV, 2017.

INCRA. Instituto Nacional de Colonização e Reforma Agrária Relatório Assentamentos: Informações Gerais. Macapá: INCRA, 2016

INPE. Instituto Nacional de Pesquisas Espaciais Monitoramento da cobertura florestal da Amazônia por satélites: sistemas PRODES, DETER, DEGRAD E QUEIMADAS 2007-2008. São José dos Campos: INPE, 2008.

KITAMURA, P. C.. A Amazônia e o Desenvolvimento Sustentável. São Paulo: EMBRAPA, 1994.

LEMOS, A. L. F.; SILVA, J. A.. Desmatamento na Amazônia Legal: evolução, causa, monitoramento e possibilidades de mitigação através do fundo Amazônia. Floresta e Ambiente, Rio de Janeiro, v.18, n.1, p.98-108, 2011. Dol: http://doi.org/10.4322/floram.2011.027

LUZ, N.. Análise espacial como subsídio à recuperação de ecossistemas apoiada na ecologia de paisagens e imagens Ikonos. Dissertação (Mestrado em Engenharia Florestal) Universidade Federal do Paraná, Curitiba, 2002.

MARGULIS, S.. Causas do desmatamento na Amazônia brasileira. Brasília: The World Bank, 2003.

MILARÉ, É.. Direito do Ambiente: A Gestão Ambiental em Foco (Doutrina, Jurisprudência e Glossário). 6 ed. São Paulo: Revista dos Tribunais, 2009.

WALKER, R.; MORAN, E.; ANSELIN, L.. Deforestation and cattle ranching in the Brazilian Amazon: external capital and household processes. World Development, v.28, n.4, p.683699, 2000.

A CBPC - Companhia Brasileira de Produção Científica (CNPJ: 11.221.422/0001-03) detém os direitos materiais desta publicação. Os direitos referem-se à publicação do trabalho em qualquer parte do mundo, incluindo os direitos às renovações, expansões e disseminações da contribuição, bem como outros direitos subsidiários. Todos os trabalhos publicados eletronicamente poderão posteriormente ser publicados em coletâneas impressas sob coordenação da Sustenere Publishing, da Companhia Brasileira de Produção Científica e seus parceiros autorizados. Os (as) autores (as) preservam os direitos autorais, mas não têm permissão para a publicação da contribuição em outro meio, impresso ou digital, em português ou em tradução. 